\title{
Suitability Assessment of Karst Rocky Desertification Control Patterns in Karst Counties of Guangxi Zhuang Autonomous Region
}

\author{
Yan Yan ${ }^{1,2, \text { a }}$, Baoqing $\mathrm{Hu}^{1,2}$, Deguang Wang ${ }^{3}$ \\ ${ }^{1}$ Key laboratory of Environment Change and Resources Use in Beibu Gulf, (Guangxi \\ Teachers Education University), Ministry of Education, Nanning, Guangxi, China; \\ ${ }^{2}$ Guangxi Key Laboratory of Earth Surface Processes and Intelligent Simulation, Nanning, \\ Guangxi, China; \\ ${ }^{3}$ Guangxi University of Finance and Economics, Nanning, Guangxi, China; \\ ayanyan168166@163.com
}

Key words: Karst area of Guangxi; control patterns; fuzzy comprehensive assessment; regionalization

\begin{abstract}
The State Council officially replied the "planning framework of comprehensive controls for karst rocky desertification regions" during 11th Five Year Plan. The counties in Guangxi appointed by the planning framework were taken as the study objects. First, the index system of suitability assessment was established and the fuzzy comprehensive assessment was conducted. The control patterns were regionalized by a bottom up method. Second, the karst rocky desertification control patterns under different geographic background were collected and summarized. The control patterns were generalized by a top down method. Finally, the assessment results of the two methods were compared and adjusted. Then, the karst counties of Guangxi were regionalized and the suitable control patterns for karst counties were determined.
\end{abstract}

\section{Introduction}

In Guangxi, some successful rocky desertification control patterns and techniques have been formed. But these methods are developed under different ecological, social and economic conditions [1-2]. These patterns have promotional value theoretically, but their application scopes still need to be discussed [3]. Researches on the suitability of these patterns have just started, and there is no complete suitability assessment and index system for rocky desertification control pattern.

\section{Overview of the Study Area}

Guangxi Zhuang Autonomous Region is located in the southern part of China. It is situated at 104 degrees, 28 minutes to 112 degrees, 3 minutes east longitude and 20 degrees, 54 minutes to 26 
degrees, 23 minutes north latitude. Guangxi is bordered by the Yunnan-Guizhou Plateau to the west, and hilly areas in Guangdong and Guangxi to the east. The terrain of Guangxi is high in northwest and low in southeast. Mountain, plateau and hills cover most of the area. Guangxi has a subtropical climate with high temperature and rainfall. Guangxi is a typical area of karst topography, which covers $37.8 \%$ of the total area [4].

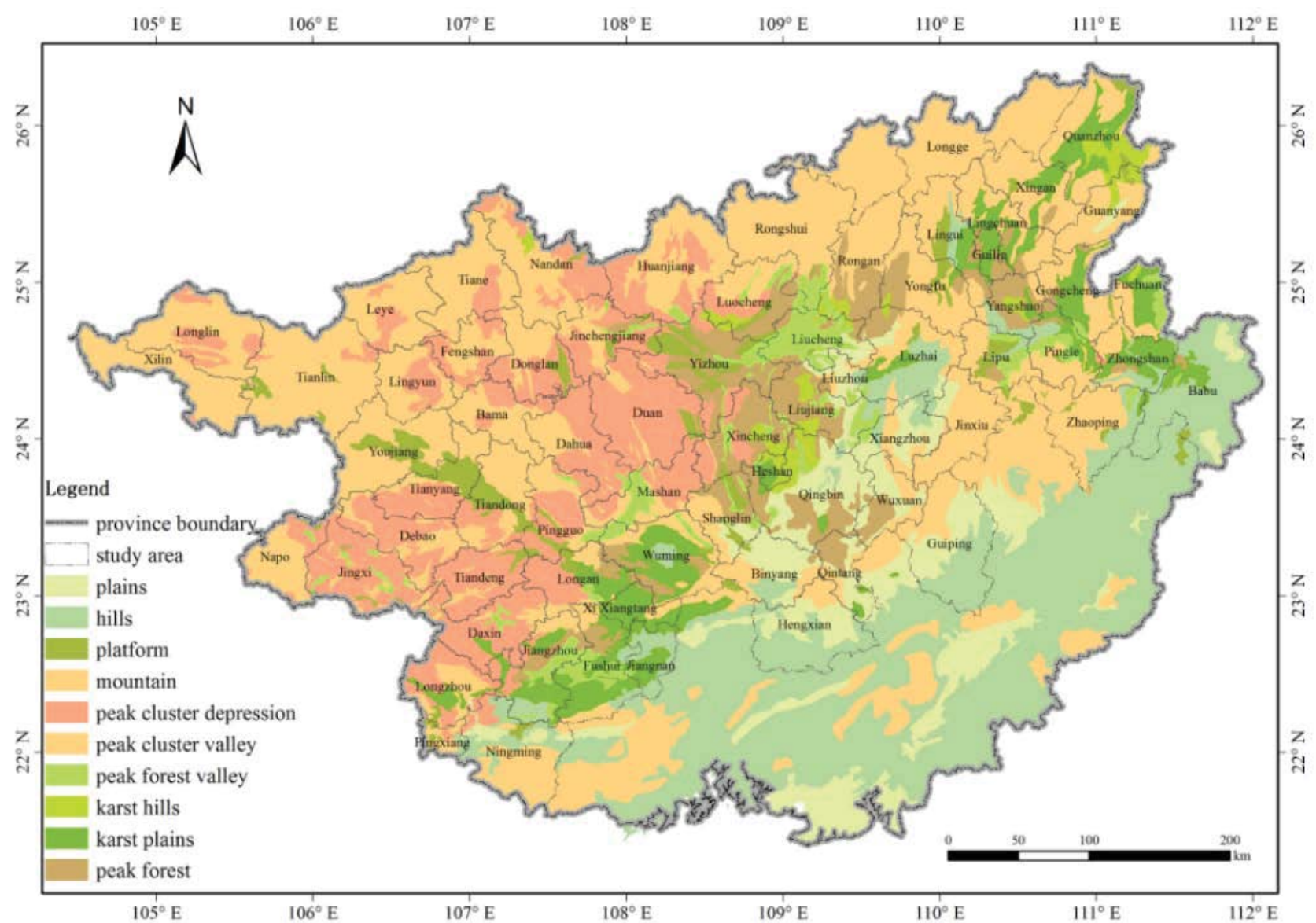

Fig.1 Location map of the study area

\section{Research Materials and Methods}

Data sources. Researchers use thematic maps, including distribution map of Karst landform, distribution map of rocky desertification, distribution map of rocky desertification degree, distribution map of lithological characters, distribution map of soil type, and the distribution map of underground rivers in karst areas. Statistics data comes from Guangxi Statistical Yearbook and Guangxi Local Record-Karst Areas, etc. 
Suitability assessment methods. Evaluation index system. The condition of each county is examined and measured from three aspects: ecology, economy and society. [5] Corresponding clustering indexes are selected, and the evaluation index system is divided into 3 levels: (1) the target layer; (2) the sub-target layer, including ecological, economic and social conditions; (3) the index layer, including specific evaluation indexes (Table 1).

Table 1 Index system of suitability assessment for control patterns

\begin{tabular}{|c|c|c|c|}
\hline TARGETS & SUB-TARGETS & INDEXES & $\begin{array}{c}\text { INDEX QUANTIFICAT } \\
\text { ION }\end{array}$ \\
\hline & $\begin{array}{l}\mathrm{U}_{1} \text { ECOLOGICAL } \\
\text { CONDITIONS }\end{array}$ & $\begin{array}{c}\mathrm{U}_{11} \text { RATIO OF ROCKY } \\
\text { DESERTIFICATION AREAS (\%) } \\
\text { U }_{12} \text { LITHOLOGIC CHARACTERS (\%) } \\
\text { U }_{13} \text { LANDFORM (\%) } \\
\text { U }_{14} \text { RATIO OF } \geq 25 \text { HILLSIDE LANDS } \\
\text { U }_{15} \text { SOIL TYPE (\%) } \\
\text { U }_{16} \text { LENGTH OF UNDERGROUND } \\
\text { RIVER (M) } \\
\text { U }_{17} \text { SOWN AREA OF CROPS }\left(\mathrm{KM}^{2}\right)\end{array}$ & $\begin{array}{l}\text { RATIO } \\
\text { CARBONATITE } \\
\text { RATIO OF KARST } \\
\text { AREAS } \\
\text { RATIO OF LIME SOIL }\end{array}$ \\
\hline \multirow[t]{2}{*}{$\begin{array}{l}\text { INDEX } \\
\text { SYSTEM OF } \\
\text { SUITABILITY } \\
\text { ASSESSMEN } \\
\text { T FOR } \\
\text { CONTROL } \\
\text { PATTERNS }\end{array}$} & $\begin{array}{c}\mathrm{U}_{2} \\
\text { ECONOMIC CON } \\
\text { DITIONS }\end{array}$ & $\begin{array}{c}\mathrm{U}_{21} \text { GDP PER CAPITA (YUAN) } \\
\text { U }_{22} \\
\text { RURAL PER CAPITA NET INCOME } \\
\text { (YUAN) } \\
\text { U }_{23} \text { ECONOMIC DENSITY (TEN } \\
\text { THOUSAND YUAN/ KM }{ }^{2} \text { ) } \\
\text { U }_{24} \text { PROPORTION OF PRIMARY } \\
\text { INDUSTRY }(\%)\end{array}$ & \\
\hline & $\begin{array}{c}\mathrm{U}_{3} \\
\text { SOCIAL CONDITI } \\
\text { ONS }\end{array}$ & $\begin{array}{c}\text { U }_{31} \text { ADMISSION RATE }(\%) \\
\mathrm{U}_{32} \text { DENSITY OF POPULATION (ONE } \\
\left.\text { PERSON/ KM }{ }^{2}\right) \\
\mathrm{U}_{33} \text { DENSITY OF HIGHWAY }\left(\mathrm{KM} / \mathrm{KM}^{2}\right) \\
\mathrm{U}_{34} \text { QUALITY AND COORDINATION } \\
\text { DEGREE OF INHABITANTS }\end{array}$ & EDUCATION DEGREE \\
\hline
\end{tabular}

Fuzzy clustering analysis method. Data standardization. Setting domain $U=\{x 1, x 2, \ldots, x n\}$ as the classified object, then each object has $m$ indexes to express its character, namely $\mathrm{x} i=\{\mathrm{xi} 1, \mathrm{xi} 2, \ldots$ $\mathrm{Xim}\}$, of which $\mathrm{i}=1,2, \ldots, \mathrm{n}$. The original data matrix can be obtained as following (formula 1).

$$
\left(\begin{array}{cccc}
\mathrm{x}_{11} & \mathrm{x}_{12} & \ldots & \mathrm{x}_{1 \mathrm{~m}} \\
\mathrm{x}_{21} & \mathrm{x}_{22} & \ldots & \mathrm{x}_{2 \mathrm{~m}} \\
\vdots & \vdots & \vdots & \vdots \\
\mathrm{x}_{\mathrm{n} 1} & \mathrm{x}_{\mathrm{n} 2} & \ldots & \mathrm{x}_{\mathrm{nm}}
\end{array}\right)
$$

Establishing fuzzy similarity relation. Assuming that the kth index of the classification object $i$ as $\mathrm{x}_{\mathrm{ik}}(\mathrm{i}=1,2, \ldots, \mathrm{m} ; \mathrm{k}=1,2, \ldots, \mathrm{n})$, using angle cosine method to measure the similarity between the ith and $j$ th classification objects, $r_{i j}$ in formula 2. [6] 


$$
\mathrm{r}_{\mathrm{ij}}=\cos \theta_{\mathrm{ij}}=\frac{\sum_{\mathrm{k}=1}^{\mathrm{n}} \mathrm{x}_{\mathrm{ik}} \mathrm{x}_{\mathrm{jk}}}{\sqrt{\sum_{\mathrm{k}=1}^{\mathrm{n}} \mathrm{x}_{\mathrm{ik}}^{2}} \sqrt{\sum_{\mathrm{k}=1}^{\mathrm{n}} \mathrm{x}_{\mathrm{jk}}^{2}}}(\mathrm{i}, \mathrm{j}=1,2, \ldots, \mathrm{m})
$$

Then establishing the fuzzy similarity relation in formula 3,

$$
\mathrm{R}=\left(\mathrm{r}_{\mathrm{ij}}\right) \mathrm{m} \times \mathrm{m}=\left(\begin{array}{cccc}
\mathrm{r}_{11} & \mathrm{r}_{12} & \ldots & \mathrm{r}_{1 \mathrm{~m}} \\
\mathrm{r}_{21} & \mathrm{r}_{22} & \ldots & \mathrm{r}_{2 \mathrm{~m}} \\
\vdots & \vdots & \vdots & \vdots \\
\mathrm{r}_{\mathrm{m} 1} & \mathrm{r}_{\mathrm{m} 2} & \ldots & \mathrm{r}_{\mathrm{mm}}
\end{array}\right)
$$

Transforming the fuzzy similarity relation $\mathbf{R}$ into fuzzy equivalence relation $t(R)$. To achieve clustering analysis, the fuzzy similarity relation $\mathrm{R}$ must be transformed into fuzzy equivalence relation $\mathrm{t}(\mathrm{R})$ through using the property of transfer closed. The transformation method is square $\mathrm{R}$, namely:

$$
\begin{aligned}
& \mathrm{R}^{2}=\mathrm{R}^{\mathrm{o}} \mathrm{R} \\
& \mathrm{R}^{4}=\mathrm{R}^{2}{ }^{\mathrm{o}} \mathrm{R}^{2}
\end{aligned}
$$

There must be a natural number $k$, making $\mathrm{R}^{2 \mathrm{k}}=\mathrm{R}^{2}{ }^{\mathrm{o}} \mathrm{R}^{2}=\mathrm{R}^{\mathrm{k}}$

Clustering at different levels of cut sets. The fuzzy equivalence relation $t(R)$ is used to cluster at different levels of cut sets. Different classifications can be get from different $\lambda \notin[0$. In the dynamic clustering graph, the value of $\lambda$ is adjusted to get the proper classification.

\section{Results and Discussions}

Summary of rocky desertification control patterns in Guangxi. Relatively typical and effective control patterns are selected and analyzed top-down from macro perspective. The initial extension range of each pattern is predicted and inferred according to geographic conditions of each pattern and the structure of controlling project [7].

First is the compound ecological agricultural pattern in Guohua, Pingguo County. In this pattern, economic crops are planted in bottomland, economic forest and fruit trees are cultivated in peak clusters at the foot of mountains. Economic crops which can conserve water and soil grow in narrow mountain pass; protection forest and water conservation forest are planted in the upper-middle part of peak clusters. This pattern can be promoted in peak cluster depression and low mountain areas in the southwest of Guangxi Province.

Second is the ecological migration and mixed farming pattern in Kenfu and Guzhou of Huanjiang County. Overloading populations in karst mountains are guided to migrate to hilly areas 
with low population density. Appropriate industrial activities are carried out to in immigrant areas to increase farmers' income. The pattern can be applied to peak cluster depression and plateau slope in the northwest of Guangxi.

Third is the ecological agricultural pattern in Nongla, Mashan County which aims to restore the original appearance. In serious rocky desertification areas, closed forest project and forest plantation methods are used. In areas with low degree of rocky desertification, soil improvement is carried out, and the comprehensive planting of forest, fruit and herb is developed. The pattern can be applied in peak cluster depressions, gentle hills and plain areas in the southwest of Guangxi.

Fourth is the ecological tourism management pattern in peak cluster depressions of Qibainong, Dahua County. Peak cluster depressions, nearby karst cave and karstic water landscapes are exploited to form tourism landscape system; medicinal herb planting industry, forestry and fruit industry, as well as animal husbandry are developed to improve income level. This pattern can be applied to peak cluster depressions and plateau slopes in the northwest of Guangxi.

Fifth is the ecological agriculture pattern of Gongcheng, namely the pattern of "breeding - biogas - planting". The development strategy considers "planting as the key point, biogas as the link, and breeding as the foundation". It can be applied to peak forest plains in the northeast of Guangxi, and gentle hills as well as plain areas in the centre of Guangxi.

\section{Suitability assessment and regionalization of rocky desertification control patterns.} Assessment result of fuzzy clustering. Square $R$, we can get that when $k=8, R^{8}=R^{16}$. Thus, the fuzzy similarity matrix when $k=8$ is selected as the fuzzy equivalence matrix. Selecting the intercept of $\lambda=0.846$ to cluster, then clustering result is obtained (Figure 2 ).

However, there are some differences between the results from the top-down subjective prediction and from the bottom-up fuzzy cluster analysis (Figure 2). They need to be compared and adjusted to get the final assessment result.

Regionalization result of rocky desertification control patterns. According to the result of fuzzy clustering, Xilin County, Tianlin County, Youjiang District and Tian'e County which located in the northwest of Guangxi, are classified to the same group with counties in the northeast of Guangxi. Landscapes in these counties belong to karst plateau slope which is characteristic in the northwest of Guangxi, and the rocky desertification degree of these counties is relatively serious. Therefore, Xilin County, Tianlin County, Tian'e County, Dahua Yao Autonomous County, Du'an Yao Autonomous County are classified to the same group with counties in the northwest. Youjiang District, Tiandong County are classified to the same group with peak cluster depression counties in the southwestern areas of Guangxi. 


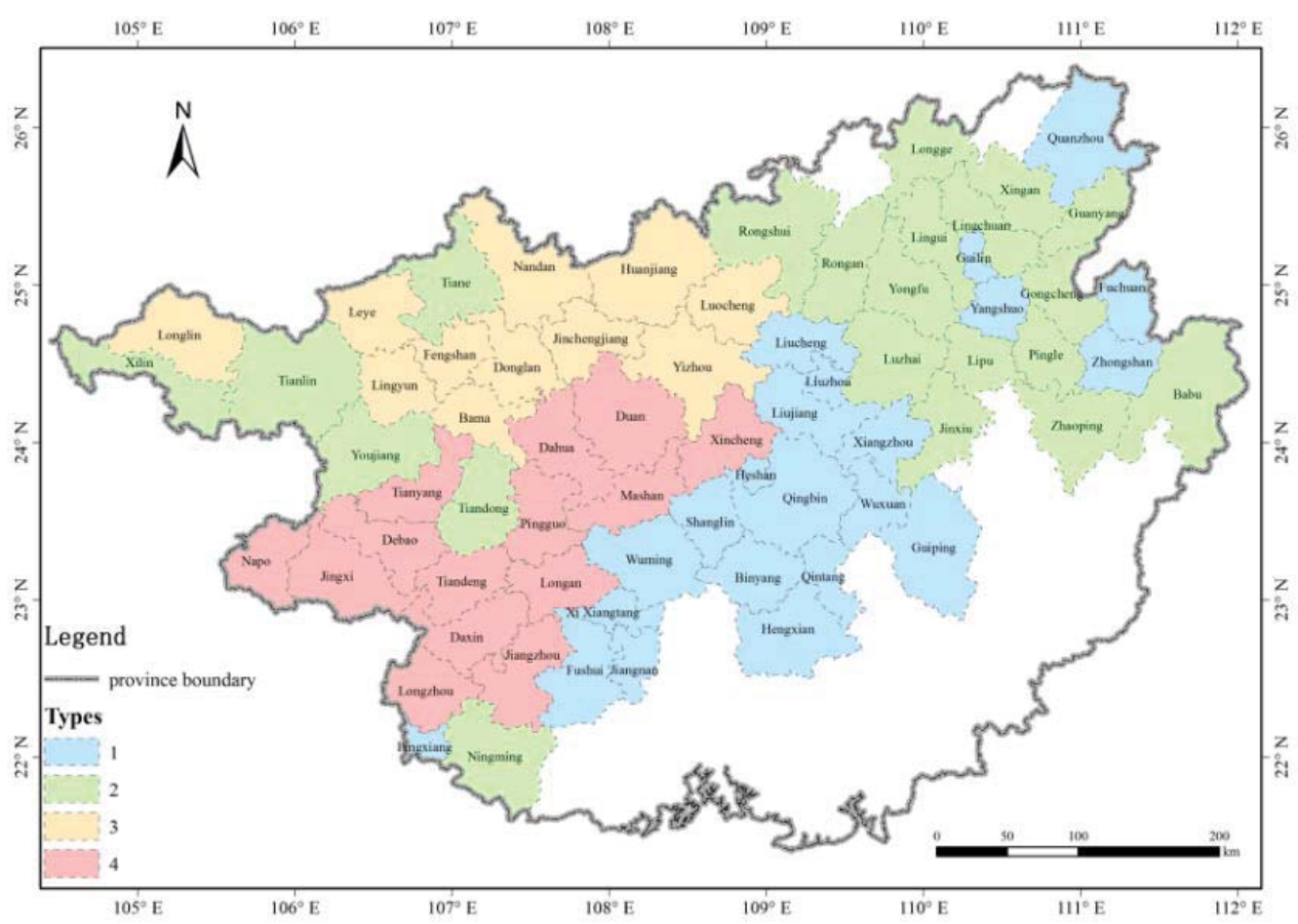

Fig.2 The fuzzy clustering result of control patterns

Pingxiang City and Ningming County are located in the southwest of Guangxi, and classified in the same group with counties in the northeast and central part of Guangxi at first. But actually, these areas are covered with gentle hills and valleys. So they are adjusted to the group of peak forest in low hilly plains and karst basin in the central part of Guangxi. Then, the final results of suitability assessment and regionalization of rocky desertification control patterns are obtained. (Figure 3)

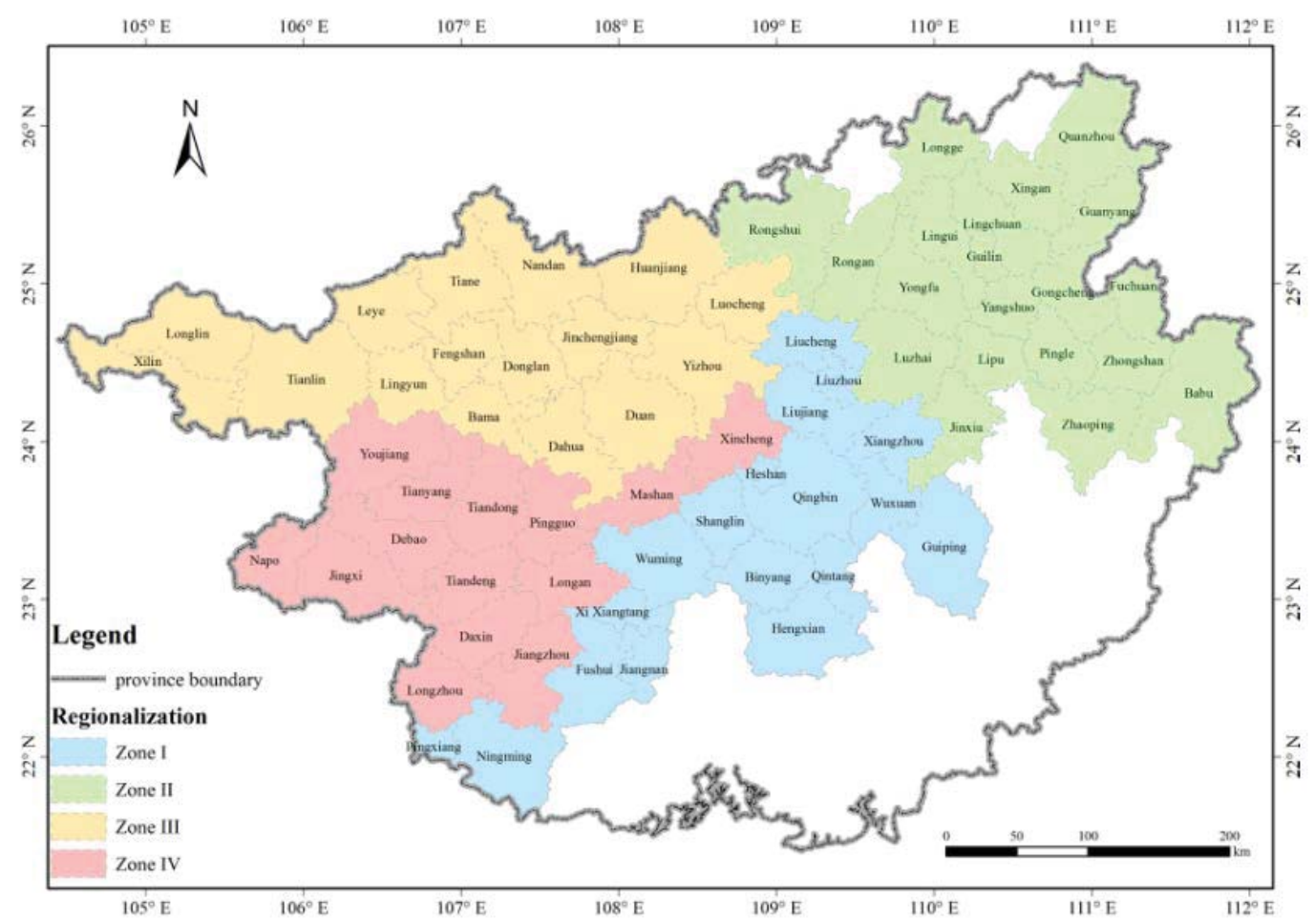

Fig.3 The regionalization result of the control patterns 
The clustering results are divided into 4 zones. The four regions are named according to their relative geographical locations and the type of karst landforms.

Zone I: karst basin and peak forest plain area in South Central Guangxi

According to the geographical background and other conditions of this area, Gongcheng pattern can be applied here. The development strategy considers "planting as the key point, biogas as the link, and breeding as the foundation". At the same time, comprehensive ecological agriculture pattern in hilly and mountainous areas can also be developed to make full use of vertical space.

Zone II: peak forest plain and mountain valley area in Northeast Guangxi

The area is around of natural resources and forest landscapes, and serves as the key area of tourism industry development. The corresponding control patterns include Gongcheng pattern, and the combination of breeding and planting. But the special and important ecological location of the district calls for engineering measures such as drainage ditch and embankment building to improve its prevention ability against natural disasters like drought and flood.

Zone III: peak cluster depression and plateau slope area in the Northwest of Guangxi

Corresponding patterns to this area include ecological agriculture pattern of Mashan. According to the special landscape structures and ecological environment of karst mountains, different crops and vegetation are planted in different part of peak cluster depressions, in order to improve the ecological environment, and restore forests' function of water conservation.

Kenfu pattern can also be promoted. Overloading populations in karst mountains can be guided to migrate to new developed districts with low population density and lots of hilly wastelands. In this way, relative industries can be developed, while the environment can be protected. The structural adjustment on land usage can be applied to original peak cluster areas.

Zone IV: peak cluster depression and low mountainous area in Southwest of Guangxi. The corresponding patterns of this area include ecological agriculture pattern of Pingguo. The key point of this pattern is the exploitation of karstic water, including surface spring and water at the bottom of depression. Different crops and vegetation are planted in different geological positions. The other suitable pattern is the ecological tourism management pattern in peak cluster depressions of Qibainong, Dahua County, which can effectively control rocky desertification, prevent ecological environment, and promote the development of local economy.

Suitable control pattern of each area can be got through comprehensive analysis, but there's no single perfect pattern for each area. They need the combination of several patterns to achieve the best control effects. 


\section{Acknowledgement}

Fund Project: This project is supported by National Key Development Program for Fundamental Researches (Project No.: 2016YFC0502400), National Natural Science Foundation of China (Project No.: 40871250, 71361001) and Natural Science Foundation of Guangxi Zhuang Autonomous Region (Project No.: 2015jjBA50056).

\section{References}

[1] Zhong-cheng Jiang, Jian-guo Pei \& Ri-yaun Xia, et al. Progresses and important activities of karst research during the 11th Five-Year Plan in China [J]. CARSOLOGICA SINICA, 2010, 29(4): 349-354.

[2] Ying Du. Exploration and Practice on Comprehensive Control of Karst Rocky Desertification [J]. Industry of China, 2011,7:16-19.

[3] Jun-yi Zhang, Ming-hong Dai \& La-chun Wang, et al. Rocky desertification control issues in the context of priority for ecological function in karst areas of southwest China [J]. Carsologica Sinica, 2014, 33(4): 464-472.

[4] Compilation Committee of Local Chronicles of Guangxi Zhuang Autonomous Region. Guangxi Tong Zhi-Introduction of Karst [M]. Guangxi People's Publishing House. 2000.

[5] Xiao-qing Yang, Bao-qing Hu \& Shao-ying Cao. Analysis of Effect of Ecological Management of Rocky Desertification in Karst Regions Based on Fuzzy Comprehensive Evaluation Model-A Case Study of Du'an County in Guangxi [J]. JOURNAL OF ECOLOGY AND RURAL ENVIRONMENT, 2008, 24(2): 22-24.

[6] Ming-hong Dai, La-chun Wang \& Hao Tang. Research on Water Resources Carrying Capacity in Karst Areas Based on Multilevel Fuzzy Comprehensive Evaluation Model [J]. Bulletin of Soil and Water Conservation, 2016, 36(1): 151-156.

[7] Kun-feng Deng, Zhao-jun Liu \& Shi-zhen Xiao, et al. A Research of Construction and Evaluation of an Efficiency Index System to Prevent and Control the Rocky Desertification Area--With a special Reference to Guanling-Zhenfeng Huajiang Demonstration Area [J]. Chinese Agricultural Science Bulletin, 2012, 28(17): 187-194. 